\title{
Primary pulmonary invasive mucinous adenocarcinoma with sigmoid colon metastasis:a case report and literature review
}

\section{Jian Fang}

wuhan university zhongnan hospital

hui juan hu ( $\nabla$ 59698684@qq.com )

Zhongnan Hospital of Wuhan University https://orcid.org/0000-0001-9774-1785

hong cao

Wuhan University Zhongnan Hospital department of pathology

\section{Case report}

Keywords: computed tomography, invasive mucinous adenocarcinoma, colonic metastasis, Immunohistochemistry

Posted Date: December 21st, 2020

DOI: https://doi.org/10.21203/rs.3.rs-131103/v1

License: (a) (1) This work is licensed under a Creative Commons Attribution 4.0 International License. Read Full License 


\section{Abstract}

Background: Invasive mucinous carcinoma is a very rare tumor. The colonic metast-asis of IMA is more infrequent. So far, no literatures are published.

Case presentation: We report a case of a patient with invasive mucinous adenocarci-noma. After serial months of chemitherapy, the sigmoid colonic metastasis was detected.

Conclusions: Symptoms and CT findings can initially be subtle, histological examination remains the gold standard for the definitive diagnosis. Patients with high grade primary lung cancer may have gastrointestinal metastases, therefore their gastrointestinal should be examined to allow early detection and treatment.

\section{Background}

Lung cancer remains the leading cause of cancer-related deaths globally[1]. Adenocarcinoma represents the most common lung cancer subtype[2]. Among all lung adenocarcinomas, invasive mucinous adenocarcinoma (IMA) is relatively rare, accounting for only $2 \sim 5 \%$ of lung invasive adenocarcinomas[3]. Nearly $50 \%$ patients with lung cancer have been found to have distant metastases at the time of death [4]. The common metastatic sites originating from lung cancer include lung itself, liver, brain, adrenal gland, and bone[5]. It is extremely rare to find colonic metastasis [6, 7], only a few case reports have been published[8-10]. But none have been reported of primary pulmonary mucinous adenocarcinoma with colonic metastasis, perhaps due to the rarity of IMA and colonic metastasis. In the present study, we report the first case of primary pulmonary mucinous adenocarcinoma with sigmoid colon metastasis. We also review the published literature of primary lung cancer withsigmoid colon metastasis.

\section{Case Presentation}

The patient was a 69-year-old Chinese female. One month ago, during her physical examination, lung lesions were found. Thus, she visited the respiratory out- patient department in May, 2020. Chest CT was performed which revealed multiple ground glass nodules and bilateral consolidation shadows in both lower lungs (Fig. 1). The initial diagnosis was pulmonary inflammation, and reexamination after treatment was recommended. So she was hospitalized for more detailed tests.

She complained cough of one-month duration, associated with white mucus. Her vital signs were normal. Auscultation revealed coarse crackles in both lower lung fields. A systemic review of the occupational and travel environments did not reveal the reason for the pulmonary infiltration. She has a family history of diabetes.

The white blood cell count was $3.10 \times 10^{9} / \mathrm{L}$, C-reactive protein and procalcitonin were in the normal range. Routine blood chemistry tests were normal. Tumor markers in patients' serum were all negative. Flexible bronchoscopy was performed and no endobronchial lesions were detected. The sputum culture 
was positive, gram-positive and gram-negative bacteria were found. Tuberculosis (TB) was ruled out. The remainder of the infectious work-up including AFB smear, mycobacterial cultures, BAL fluid bacterial cultures and HIV antigen/antibody combo were negative. An autoimmune panel, including ANA, ANCA and myositis autoantibodies was negative, except ANA and anti Ro-52 (+). The patient was therefore started on cefoperazone- sulbactam and levofloxacin in addition to broad spectrum antibiotic therapy. After ten-days treatment, the patient's respiratory symptoms showed mild improvement, but the multifocal pulmonary infiltrations remained unchanged. Therefore CT-guided percutaneous lung biopsy in right lower lobe was performed. Histopathologically, the tumor consisted of abundant mucin filling the alveolar spaces and some tumor cells floating in mucin pools. Columnar mucinous epithelial cells lined thickened alveolar walls (Fig. 2), Immunohistochemistry (IHC) showed neoplastic cells positive for CK7, negative for TTF-1, CK20, CDX2, ALK(lung) and P63. We finally diagnosed invasive mucinous adenocarcinoma of the lung (moderate to poorly differentiated stage T4N2M0, stage IIIB). Further tumor mutation analysis was examined, EGFR mutation was negative and KRAS mutation at the 17 exon (p.G12 D mutation) was detected. Chemotherapy was started for pulmonary mucinous adenocarcinoma. After four cycles of treatment, in August, 2020, CT examination from chest to pelvis was performed which revealed localized thickening of sigmoid wall (Fig. 3). The patient was sent to an endoscopy room, and colonoscopy suggested the possibility of colon cancer, so biopsy was performed. IHC showed CK7(-), TTF-1(+), CK20(+), CDX2 (+) ,Ki-67(Li:80\%)(Fig. 4), CerB-2(-). Finally, metastatic lung mucinous adenocarci- noma (enteric adenocarcinoma) was diagnosed. About a month later, the patient had severe abdominal pain and passed away finally. We speculated that she was died of enterobrosis and septic shock.

\section{Discussion}

Primary pulmonary invasive mucinous adenocarcinoma (IMA) is an adeno-

carcinoma variant according to the current World Health Organization (WHO) classification of lung tumors [11], formerly known as mucinous bronchioloalveolar carcinoma (BAC), which is relatively rare [3]. IMA has a range of differences from those of invasive non-municous adenocarcinoma (INMA), including genetic, clinical, radiological and pathological characteristics. The age of IMA patients ranged between 41 and 66 years and the majority were non-smoking females [12]. Clinical features are generally nonspecific, such as cough, fever, expectoration and dyspnea etc. The symptom of coughing with white sputum may help early diagnosis of pneumonic-type adenocarcinoma[13]. In the present study, it was revealed that the patient was female and non-smoker, as well as mild coughing with white sputum when she was initially diagnosed, which were consistent with previous study[13].

IMC displays a variety of radiological presentations. According to the CT findings, IMC has been classified into three patterns[14]: $\otimes$ solitary nodules or masses; llocalized consolidation, pneumonic types; \multicentric or diffuse disease, most patients have a mixture of these features. The most common features on chest high-resolution computed tomography (HRCT) scan are predominant ground- glass opacities, consolidations, or multiple nodules[15]. Because of the nonspecific 
radiographic findings, we may usually not differentiate them from other lung diseases, such as atypical pneumonia, tuberculosis, pulmonary lymphoma or metastatic lung cancer $[15,16]$. However some studies [17-19] reported that the pneumonic types IMA had air bronchograms with stretched, sweeping, narrowed appearance and bulging of the interlobar fissure. In our report, the patient was initially misdiagnosed as focal organizing pneumonia, but after ten days of anti-inflammatory therapy, the lesions are not eliminated, ultimately we got an accurate diagnosis by percutaneous computer tomography (CT)-guided lung biopsy. we reviewed her chest CT imagings carefully, some signs were found, such as air bronchograms with a stretched, sweeping and bulging of the interlobar fissure, which can help the differential diagnosis. Percutan- eous computer tomography (CT)-guided lung biopsy appears to be an effective way to make a definitive diagnosis.

Almost $50 \%$ of non-small-cell lung cancer (NSCLC) patients present with metastatic disease at the time of diagnosis, the most common NSCLC metastatic site is bone (34\%), followed by lungs (32\%), brain (28\%), adrenalglands (17\%), liver (13\%), and extrathoracic lymph nodes (9\%) [8]. Colonic metastasis is extremely uncommon with an incidence of $0.1 \%$ [20], and about 50 unique case reports of lung cancer metastasizing to the colon have been published globally[4, 6-8, 10, 21-70], among them, squamous cell carcinoma(SqCC), lung adenocarcinomas, small cell lung carcinomas, Large-cell carcinoma, other primary lung histopathologic cell types such as sarcomatoid, pleomorphic, and unknown were confirmed as primary origins, $\mathrm{SqCC}$ is the most common origins, followed by lung carcinoma.

Immunohistochemistry is very valuable for determining the primary origins. Among those, CK7, CK20, CDX2, and TTF-1 has been proven to be diagnostic[6]. Most pulmonary adenocarcinomas are typically positive for TTF-1 and CK 7, and negative for CK 20[71-74]. Most colorectal adenocarcinomas are negative for TTF-1 and CK 7, and positive for CK 20[75-76]. However, up to $20 \%$ of lung adenocarcinomas are reported to be negative for TTF-1, and up to $30 \%$ may react positively with CK 20 . Several studies showed CDX-2 to be highly sensitive for colorectal ACA, but among lung tumors, only a rare type of pulmonary ACA, the goblet cell variant of primary mucinous (so-called colloid) ACA, has been reported to be positive for CDX-2[77]. TTF-1 is expressed only in lung cancer and thyroid cancer [77- 81]. The expression of TTF-1 rate in IMA is often lower than that in non-mucinous adenocarc- inoma. In addition, according to the report of Su et al [12], the positive rates of primary lung adenocarcinoma were $73 \%$ for TTF- $1,75 \%$ for CK7, and $0 \%$ for CK20, the positive rates of primary colon cancer were reported to be $0 \%$ for TTF-1, 7\% for CK7, and $86 \%$ for CK20. Thus, since TTF-1 expression is lacking in all adenocarci- noma types except for lung adenocarcinoma, which is very important to distinguish between primary adenocarcinoma and metastatic adenocarcinoma.

KRAS mutations are the most requent oncogenic driver mutations in IMAs (up to 86\%) [82, 83]. the most common types are G12D and G12V in IMAs [83]. KRAS mutation has been reported to be associated with invasive mucinous adenocarcinoma, formerly known as mucinous BAC [84]. For our patient, the lung lesion was immun- oreactive for $\mathrm{CK} 7$, favoring the diagnosis of lung adenocarcinoma. Negative staining of p63 rules out squamous cell carcinoma of the lung. KRAS mutation (p.G12 D mutation) was positive. The sigmoid lesion was immunoreactive for TTF-1, CK 20, CDX2. The positive expression of TTF-1 
indicated that her sigmoid tumor was metastatic from pulmonary carcinoma. Because of the primary pulmonary mucinous adenocarcinoma, CDX2 can be positive. These IHC stains can help determine the primary tumor and distinguish metastatic carcinoma from primary tumor.

\section{Conclusion}

Our report represents an exceedingly rare case of primary pulmonary invasive mucinous adenocarcinoma metastatic to sigmoid colon. Symptoms and CT findings can initially be subtle, histological examination remains the gold standard for the definitive diagnosis. Patients with high grade primary lung cancer may have gastrointestinal metastases, therefore their gastrointestinal should be examined to allow early detection and treatment.

\section{Abbreviations}

IMA : invasive mucinous adenocarcinoma; CDX2: Caudal-type homeobox 2;

CK: Cytokeratin; CT: Computed tomography; SqCC: squamous cell carcinoma

TTF: Thyroid transcription factor-1; BAC: bronchoalveolar carcinoma

NSCLC : non-small-cell lung cancer; IHC: immunohistochemical

\section{Declarations}

\section{Acknowledgements}

The authors declare that no acknowledgements have to be done.

\section{Funding}

The authors declare that no funds have been received.

Availability of data and materials

The availability of the data and material section concerning the case report is related to all the diagnostic examinations that the patients have submitted during their hospitalization. The publication of all these data has been authorized by the Medical Research Center of the wuhan university zhongnan Hospital.

\section{Authors' contributions}

Fang $\mathrm{J}$ contributed to CT scanning of the patient, collection of the clinical data and writing of the manuscript. Hu HJ contributed to edit, revised and approved the manuscript. Cao $\mathrm{H}$ contributed to histological diagnosis. All authors read and approved the final manuscript. 


\section{Competing interests}

The authors declare that they have no competing interests.

\section{Consent for publication}

The consent for publication of the manuscript and the related images from the patients and/or their relatives have been obtained.

\section{Ethics approval and consent to participate}

The ethical approval has been received by the Medical Ethics Committee, Zhongnan Hospital of Wuhan University concerning the publication of this manuscript and any accompanying images(No2019056). A copy of this document is available for review by the Editor-in-Chief of this journal.

\section{New software}

The authors declare that no new software has been used.

\section{Author details}

1.Department of radiology, Zhongnan Hospital of Wuhan University, Wuhan, China.

2.Department of pathology, Zhongnan Hospital of Wuhan University, Wuhan, China.

Correspondence to: Dr Hui-juan HU, Department of radiology, Zhongnan Hospital of Wuhan University, 169 Donghu Road, Wuhan 430071, Hubei, China.

Telephone: 13807181042

E-mail: 59698684@qq.com

\section{References}

1. Barta JA, Powell CA, Wisnivesky JP. Global epidemiology of lung cancer. Ann Glob Health. 2019;85(1):8.

2. Imielinski M, Berger AH, Hammerman PS et al. Mapping the hallmarks of lung adenocarcinoma with massively parallel sequencing. Cell. 2012;150 (6):1107-20.

3. Travis WD, Brambilla E, Noguchi M, Nicholson AG, Geisinger KR, Yatabe Y, et International Association for the Study of Lung Cancer/American Thoracic Society/European Respiratory Society international multidisciplinary classifica-tion of lung adenocarcinoma. J Thorac Oncol. 2011;6;24485.

4. Myoteri D, Dellaportas D, Zizi-Sermpetzoglou A: Colonic polyp harboring lung cancer metastasis: an unpleasant surprise. J BUON. 2015;20:933. 
5. Torre LA, Siegel RL, Jemal A. Lung cancer statistics. Adv Exp Med Biol. 2016; 893:1-19.

6. Rossi G, Marchioni A, Romagnani E, Bertolini F, Longo L, Cavazza A, et al. Primary lung cancer presenting with gastrointestinal tract involvement: clinico- pathologic and immunohistochemical features in a series of 18 consecutive cases. cases. J Thorac Oncol. 2007;2:115-20.

7. Gitt SM, Flint P, Fredell $\mathrm{CH}$, Schmitz GL. Bowel perforation due to metastatic lung cancer. J Surg Oncol. 1992;51:287-91.

8. NA Parker, C McBride, J Forge, D Lalich. Bowel obstruction caused by colonic metastasis of lung adenocarcinoma: a case report and literature review. World J Surg Oncology. 2019;17(1):63.

9. Hazim S Bukamur, Rahoma Saad , Ibrahim Shahoub , Mark Gusack, Nancy J Munn.Non-small Cell Lung Cancer with Squamous Features Metastatic to a Colonic Polyp: A Case Report of a Very Rare Presentation. Cureus, 2019; 11(6): e4810.

10. Hiroshi Sakai, Hiroyuki Egi, Takao Hinoi, Masakazu Tokunaga, Yasuo Kawagu-chi, Manabu Shinomura, et al. Primary lung cancer presenting with metastasis to the colon: a case report. World Journal of Surgical Oncology, 2012;10:127.

11. William D Travis, Elisabeth Brambilla, Allen P Burke, Alexander Marx, Andrew G Nicholson. Introduction to The 2015 World Health Organization classification of tumors of the Lung, Pleura, Thymus, and Heart. Journal of Thoracic Oncology 2015;10(9):1240-2.

12. J Liu, JF Shen, ChL Yang, P He, YB Guan, WH Liang, JX He et al. High incidence of EGFR mutations in pneumonic-type non-small cell lung cancer, Medicine (Baltimore). 2015;94 (8):e540.

13. Watanabe H, Saito H, Yokose T, Sakuma Y, Murakami S, Kondo T, et al. Relation between thin-section computed tomography and clinical findings of mucinous adenocarcinoma. Ann Thorac Surg. 2015;99:975-81.

14. Shimizu K, Okita R, Saisho S, Maeda A, Nojima Y, Nakata M. Clinicopatholo-gical and immunohistochemical featuresc of lung invasive mucinous adenocarc- inoma based on computed tomography findings. Onco Targets Ther. 2016;10: 153-63.

15. Akira M, Atagi S, Kawahara M, luchi K, Johkoh T. High resolution CT findings of diffuse bronchioloalveolar carcinoma in 38 patients. AJR.1999; 173: 1623-29.

16. Jong Wook Beom, Jong Hoo Lee. Case of invasive mucinous adenocarcinoma mimicking chronic eosinophilic pneumonia. Thorac Cancer. 2014;5(2):179-83.

17. Gandara DR, Aberle D, Lau D, et al. Radiographic imaging of bronchioloaveo-lar carcinoma: screening, patterns of presentation and response assessment. J Thorac Oncol. 2006; 1 (9 Suppl.): S20-6.

18. Bonomo L, Storto ML, Ciccotosto $C$ et al. Bronchioloalveolar carcinoma of the lung. Eur Radiol.1998; 8: 996-1001.

19. Jung Jl, Kim H, Park SH, et al. CT differentiation of pneumonic-type bronch-ioloalveolar cell carcinoma and infectious pneumonia. Br J Radiol 2001; 74: 490-4. 
20. Tamura T, Kurishima K, Nakazawa K, Kagohashi K, Ishikawa H, Satoh H. Specific organ metastases and survival in metastatic non-small-cell lung cancer. Mol Clin Oncol. 2015;3(1):217-21.

21. Wang RX, Liu KT, Pan D, Ren F, Cui W, Jiang JB, et al. Isolated sigmoid colon metastasis from lung micropapillary adenocarcinoma: a case report. Int J Clin Exp Pathol 2019;12(9):3560-3564.

22. Joshua McGuire, Faidon-Marios Laskaratos, Peter Ellery, Edward Seward. Colonic metastases from lung adenocarcinoma: An unusual endoscopic finding. Digestive and Liver Diseases 2020;52(4):463.

23. Chun-Hsien Chen, Wei-Ming Chen, Shui-Yi Tung, Cheng-Shyong Wu, Wei-Lin Tong, Kam-Fai Lee, KuoLiang Wei. Gastrointestinal metastasis from primary sarcomatoid carcinoma of the lung: a case report and review of the literature. World J Surg Oncol. 2015;13:174.

24. Franco I, Tente D, Coutinho D, Linhas R, Antunes A, Barroso A. Single symptomatic colonic metastasis as first presentation of a pulmonary mucoepidermoid carcinoma. Clin Respir J. 2016;10(4):524-9.

25. Al-Tarakji M, Feilchenfeldt J, Abdulrazzaq Haidar A, Lajos Szabados L, Abdelaziem S,Sayed A,et al. Rare occurrence of metastasis from lung cancer to the anus: case report and review of the literature. World J Surg Oncol. 2016; 14 (1):157.

26. Stylianos Vittorakis, Georgia Giannakopoulou, Konstantinos Konstantinides, Anna Daskalaki, Konstantinos Samitas. Isolated colonic metastasis two years after resection of stage IA primary adenocarcinoma of the lung: A case report. Respir Med Case Rep. 2018; 25: 86-88.

27. Ana Isabel Gonzalez-Tallon, Jorge Vasquez-Guerrero, Maria Angeles Garcia-Mayor. Colonic Metastases From Lung Carcinoma: A Case Report and Review of the Literature. Gastroenterology Res. 2013; 6(1): 29-33.

28. Hai-Zhou Lou, Chun-Hua Wang, Hong-Ming Pan, Qin Pan, Jin Wang. Colonic metastasis after resection of primary squamous cell carcinoma of the lung: a case report and literature review. World J Gastroenterol. 2014; 20(19): 5930-4.

29. Carlos Eduardo Costa Almeida, Luís Simões dos Reis, Carlos Manuel Costa Almeida. Colonic metastases from small cell carcinoma of the lung presenting with an acute abdomen: A case report.Int J Surg Case Rep. 2015; 9:75-7.

30. Lin MW, Wu CT, Chang YL. Intussusception caused by intestinal metastasis from lung pleomorphic carcinoma. Ann Thorac Cardiovasc Surg. 2014; 20 (Suppl):635-8.

31. Vasa Jevremovic, Amer Abboud, Stuart Krauss.Colonic Metastasis with Anemia Leading to a Diagnosis of Primary Lung Adenocarcinoma.Case Rep Oncol Med. 2016; 2016: 5275043.

32. Nathaniel Parker, Chloe McBride, John Forge, Daniel Lalich. Colonic Metastasis of Lung Adenocarcinoma: A Case Report. Cureus. 2019; 11(3): e4341.

33. Masaya Iwamuro, Yoshio Miyabe, Kai Hanae, Kawai Yoshinari, Takata Katsuyoshi, Toshi Murakami, Mifune Hirofumi, Kazuhide Yamamoto. Regres- sion of metastatic colon tumour from primary adenocarcinoma of the lung due due to fistulisation to the bowel lumen.

Ecancermedicalscience.2014;8:412. 
34. Sadat Rashid, Dhyan Rajan, Robin Jacob, Keith Dahl, Apsara Prasad, Jaspreet Singh, et al. Colonic Metastases from Pleomorphic Carcinoma of the lung Presenting as an lleocecal Intussusception.ISRN Gastroenterol. 2011; 2011: 137139.

35. Shoji Hirasaki, Seiyuu Suzuki, Shigeki Umemura, Haruhito Kamei, Masato Okuda, Kenichiro Kudo. Asymptomatic colonic metastases from primary squamous cell carcinoma of the lung with a positive fecal occult blood test. World J Gastroenterol. 2008; 14(35):5481-3.

36. Aldo Pezzuto, Salvatore Mariotta, Federica Fioretti, Stefania Uccini. Metastasis to the colon from lung cancer presenting with severe hyponatremia and dyspnea in a young male: A case report and review of the literature. Oncol Lett. 2013; 5(5): 1477-80.

37. Glen J. Weiss, Agnes K. Liman, Jeffrey Allen, Philip Y. Cheung, Rajesh N. Ku kunoor. Squamous Cell Carcinoma of the Lung with Metastasis to the GI Tract Associated with EGFR Exon 19 Deletion. Case Rep Med. 2013; 2013: 874836.

38. William Makis, Anthony Ciarallo, Javier-A, Novales-Diaz. Lung adenocarcin- oma staged as an unknown primary presenting with symptomatic colon metastases: staging by 18 F-FDG PET/CT. Nucl Med Mol Imaging. 2011; 45 (4): 314-8.

39. Li XY, Li SH, Ma ZM, Zhao ST, Wang XD, Wen DC. Multiple gastrointestinal metastases of squamouscell lung cancer: A case report. Medicine (Baltimore). 2018; 97(24): e11027.

40. Yen-Min Huang, Tsan-Yu Hsieh, Jim-Ray Chien, Hui-Ping Chien, Pei-Hung Chang, Cheng-Hsu Wang, et al. Gastric and colonic metastases from primary lung adenocarcinoma: A case report and review of the literature.Oncol Lett. 2012 Sep; 4(3): 517-20.

41. Hu Y, Noah Feit, Huang YQ, Xu WH, Zheng Sh, Li X-ZH. Gastrointestinal metastasis of primary lung cancer: An analysis of 366 cases. Oncol Lett. 2018; 15(6): 9766-76.

42. Ono H, Okabe M, Kimura T, Kawakami M, Nakamura K, Danjo Y, Takasugi H, Nishihara H. Colonic metastasis from primary carcinoma of the lung: Report of a case and review of Japanese literature. Clin J Gastroenterol. 2009;2:89-95.

43. Bastos I, Gomes D, Gouveia H, de Freitas D. Colonic metastasis of a lung carcinoma with ileocolic fistula. J Clin Gastroenterol. 1998;26:348.

44. Naohiro Taira, Tsutomu Kawabata, Atsushi Gabe, Tomonori Furugen,Takaharu Ichi, Kazuaki Kushi,et al. Analysis of gastrointestinal metastasis of primary lung cancer: Clinical characteristics and prognosis. Oncol Lett. 2017; 14(2): 2399-404.

45. Goh BK, Yeo AW, Koong HN, Ooi LL, Wong WK. Laparotomy for acute complications of gastrointestinal metastases from lung cancer: is it a worthwile or futile effort? Surg Today. 2007;37(5):370-4.

46. Rohtesh S. Mehta, Andrew D. Liman, Vida A. Passero, Agnes K. Liman. Lung Cancer with Gastrointestinal Metastasis - Review of Theories of Metastasis with Three Rare Case Descriptions.Cancer Microenviron. 2013;6(3):203-11.

47. Yang CJ, Hwang JJ, Kang WY, et al. Gastro-intestinal metastasis of primary lung carcinoma: clinical presentations and outcome. Lung Cancer. 2006;54: 319-23. 
48. Stinchcombe TE, Socinski MA, Gangarosa LM, Khandani AH. Lung cancer presenting with a solitary colon metastasis detected on positron emission tomography scan. J Clin Oncol. 2006;24(30):493940.

49. Habesoglu MA, Oguzulgen KI, Ozturk C, Akyurek N, Memis L. A case of bronchogenic carcinoma presenting with acute abdomen. Tuberk Toraks. 2005;53(3):280-3.

50. Carroll D, Rajesh PB. Colonic metastases from primary squamous cell carcino-ma of the lung. Eur $\mathrm{J}$ Cardiothorac Surg. 2001;19(5):719-20.

51. Joffe N. Symptomatic gastrointestinal metastases secondary to bronchogenic carcinoma. Clin Radiol. 1978;29(2):217-25.

52. Gateley CA, Lewis WG, Sturdy DE. Massive lower gastrointestinal hemorrhage secondary to metastatic squamous cell carcinoma of the lung. Br J Clin Pract. 1993;47:276-7.

53. Brown KL, Beg RA, Demany MA, Lacerna MA. Rare metastasis of primary bronchogenic carcinoma to sigmoid colon: report of a case. Dis Colon Rectum. 1980;23(5):343-5.

54. Smith HJ, Vlasak MG. Metastasis to the colon from bronchogenic carcinoma. Gastrointest Radiol. 1978;2(4):393-6.

55. Xiangtao M, Liwei Y, Jing F, Shan W, Ruyi D, Zhirong C. A case report of colonic metastasis of undifferentiated lung cancer. Chin J Clin Oncol. 2006; 33:358.

56. Xiangtao M, Liwei Y, Jing F, Shan W, Ruyi D, Zhirong C. Colonic metastasis of squamous cell lung cancer: a case report and review. Cancer Res Prev Treat. 2006;33:631.

57. Cedres S, Mulet-Margalef N, Montero MA, Martinez P, Martinez A, Felip E. Rectal metastases from squamous cell carcinoma: a case report and review of the literature. Case Rep Med. 2012;2012:947524.

58. Azevedo CR, Cezana L, Moraes ES, Begnami MD, Junior Paiva TF, Dettino AL, Fanelli MF. Synchronous thyroid and colon metastases from epidermoid- carcinoma of the lung: case report. Sao Paulo Med J. 2010;128:371-4.

59. Ma XT, Yu LW, Fu J. Paraneoplastic syndromes of hypercalcemia and leukocytosis associated with colonic metastases from squamous cell carcinoma of the lung. Int J Color Dis. 2008;23(1):129-30.

60. Rouhanimanesh $Y$, Vanderstighelen $Y$, Vanderputte $S$, Cools $P$, Wassenaar $H, V$ allaeys J. Intraabdominal metastases from primary carcinoma of the lung. Acta Chir Belg. 2001;101(6):300-3.

61. Wegener M, Borsch G, Reitemeyer E, Schafer K. Metastasis to the colon from primary bronchogenic carcinoma presenting as occult gastrointestinal bleeding-report of a case. Gastroenterol. 1988;26(7):358-62.

62. Chien Ter Hsing, Ha Yeon Kim, Jung Hyun Lee, JinSeok Chang, et al. Gastrointestinal metastasis from a primaryadenocarcinoma of the lung presenting with acute abdominal pain. Korean $\mathrm{J}$ Gastroenterol. 2012;59(5):382-5.

63. Ceretti AP, Goi G, Barabino M, De Nicola E, Strada D, Bislenghi G, Opocher E. Colonic metastasis from primary carcinoma of the lung. Case report. Ann Ital Chir. 2011;82:229-32. 
64. Yang X, Zhou XM, Fu WF, Pan YG, Zhao J, et al. Colonic metastasis from primary lung adenocarcinoma: case report and review of the literature. Med Oncol. 2012;29(2):644-7.

65. Weng MW, Wang HC, Chiou JC, Lin SL, Lai RS. Colonic metastasis from a primary adenocarcinoma of the lung presenting with acute abdominal pain: a case report. Kaohsiung J Med Sci. 2010;26(1):40-4.

66. Pozzato P, Salerno A, Cancellieri A, Ventrucci M. Colonic metastasis from a primary adenocarcinoma of the lung presenting with acute abdominal pain. Dig Liver Dis. 2012;44(6):e11.

67. Ahn SE, Lee HL, Lee OY, Yoon BC, Choi HS, Hahm JS, Park SW, et al. Colonic metastasis from primary lung adenocarcinoma. Korean J Gastroenterol. 2009;53(2):121-5.

68. Jianguo S, Xiufeng Z, Qingmei J. A case report of rectal metastasis of small cell lung cancer. Chin J Cancer Prev Treat. 2000;7:369.

69. Johnson AO, Allen MB. Rectal metastases from small cell lung cancer. Respir Med. 1995;89(3):2235.

70. Polak M, Kupryjanczyk J, Rell KW. A rare case of colonic perforation in a sole site of latent lung cancer metastasis. Pol Tyg Lek. 1990;45(8-9):179-81.

71. Di Loreto C, Di Lauro V, Puglisi F, Damante G, Fabbro D, Beltrami CA. Immunocytochemical expression of tissue specific transcription factor-1 in lung carcinoma. J Clin Pathol 1997;50:30-2.

72. Wang NP, Zee S, Zarbo RJ, et al. Coordinate expression of cytokeratins 7 and 20 defines unique subset of carcinomas. Appl Immunohistochem.1995;3:99-107.

73. Chu P, Wu E, Weiss LM. Cytokeratin 7 and cytokeratin 20 expression inepithelial neoplasms: a survey of 435 cases. Mod Pathol.2000;13:962-72.

74. Loy TS, Calaluce RD. Utility of cytokeratin immunostaining in separating pulmonary adenocarcinomas from colonic adenocarcinomas. Am J Clin Pathol 1994;102:764-7.

75. Berezowski K, Stastny JF, Kornstein MJ. Cytokeratin 7 and 20 and carcinoem-bryonic antigen in ovarian and colonic carcinoma. Mod Pathol 1996;9:426-9.

76. Rossi G, Murer B, Cavazza A, et al. Primary mucinous (so called colloid) carcinomas of the lung. A clinicopathologic and immunohistochemical study with special reference to $\mathrm{Cdx}-2$ homeobox gene and MUC2 expression. Am J Surg Pathol. 2004;28:442- 52.

77. Tot T. Cytokeratins 20 and 7 as biomarkers: usefulness in discriminating primary from metastatic adenocarcinoma. Eur J Cancer. 2002;38:758-63.

78. Su YC, Hsu YC, Chai CY. Role of TTF-1, CK20, and CK7 immunohisto-chemistry for diagnosis of primary and secondary lung adenocarcinoma. Kaohsiung J Med Sci. 2006;22:14-9.

79. Gurda GT, Zhang L, Wang Y, et al. Utility of five commonly used Immunohisto-chemical markers TTF1, Napsin A, CK7, CK5/6 and P63 in primary and meta-static adenocarcinoma and squamous cell carcinoma of the lung: a retrospective study of 246 fifine needle aspiration cases. Clin Transl Med 2015;4:16. 
80. Chhieng DC, Cangiarella JF, Zakowski MF, et al. Use of thyroid transcription factor 1, PE-10, and cytokeratins 7 and 20 in discriminating between primary lung carcinomas and metastatic lesions in fine-needle aspiration biopsy specimens. Cancer. 2001;93:330-6.

81. Cai YC, Banner B, Glickman J, et al. Cytokeratin 7 and 20 and thyroid transc- ription factor 1 can help distinguish pulmonary from gastrointestinal carcinoid and pancreatic endocrine tumors. Hum Pathol 2001;32:1087-93.

82. Nakaoku T, Tsuta $\mathrm{K}$, Ichikawa $\mathrm{H}$, et al. Druggable oncogene fusions in invasive mucinous lung adenocarcinoma. Clin Cancer Res 2014;20:3087-93.

83. Shim HS, Kenudson M, Zheng Z, et al. Unique Genetic and Survival Characteristics of Invasive Mucinous Adenocarcinoma of the Lung. J Thorac Oncology. 2015;10:1156-62.

84. Kyuichi Kadota, Yi-Chen Yeh, Sandra P. D’Angelo, Andre L. Moreira, Deborah Kuk, Camelia S. Sima, Gregory J. Riely, Maria E. Mark G. Kris, Valerie W. Rusch, et al. Associations between mutations and histologic patterns of mucin in lung adenocarcinoma: invasive mucinous pattern and extracellular mucin are associated with KRAS mutation. Am J Surg Pathol. 2014 ; 38(8): 1118-27.

\section{Figures}

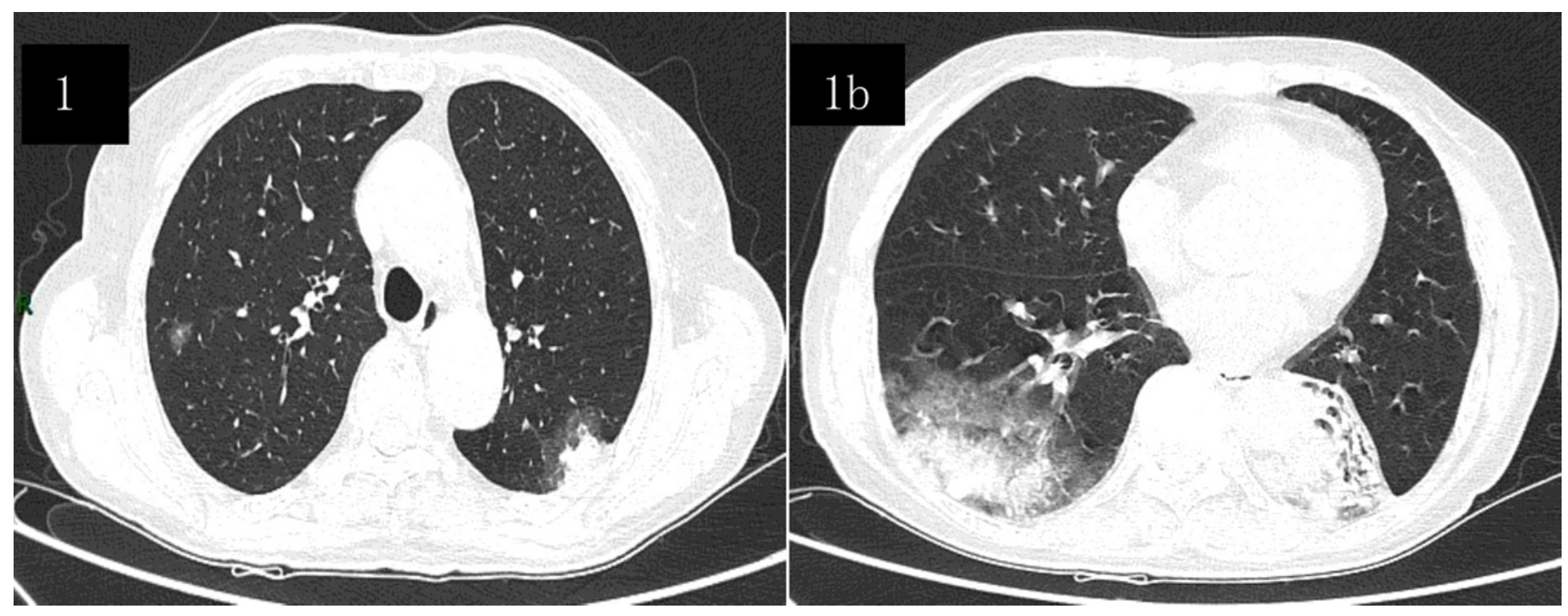

Figure 1

Chest tomography reveals lobular consolidation and ground-glass attenuation with crazy-paving appearance and subpleural dominance in both lung fields $(a-b)$. Dense peribronchial consolidation in the left lower lobe(b) . 


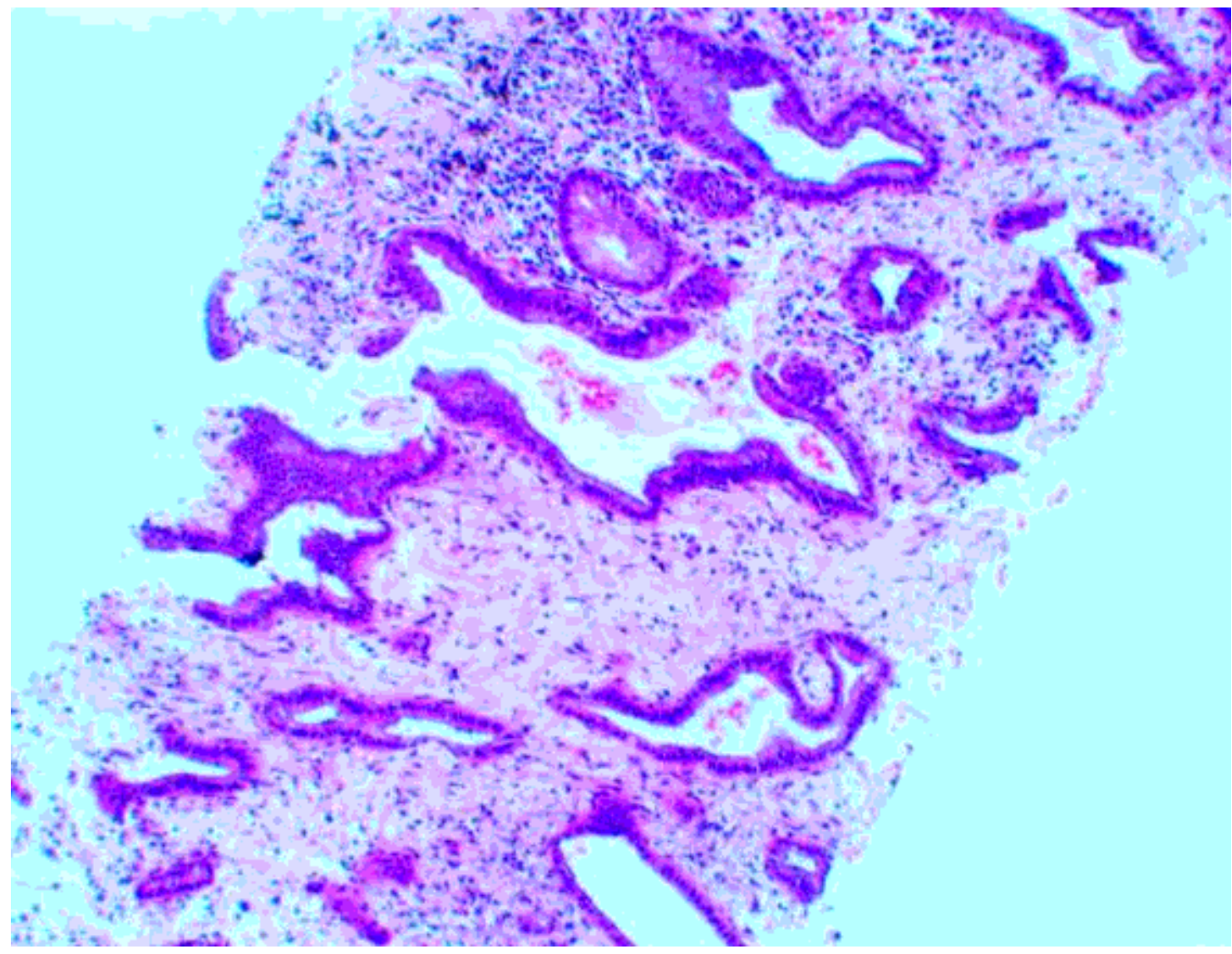

Figure 2

Microscopic examination at a magnification of $\times 200$ shows mucinous tumor cells consisting of tall columnar cells with abundant apical mucin. 


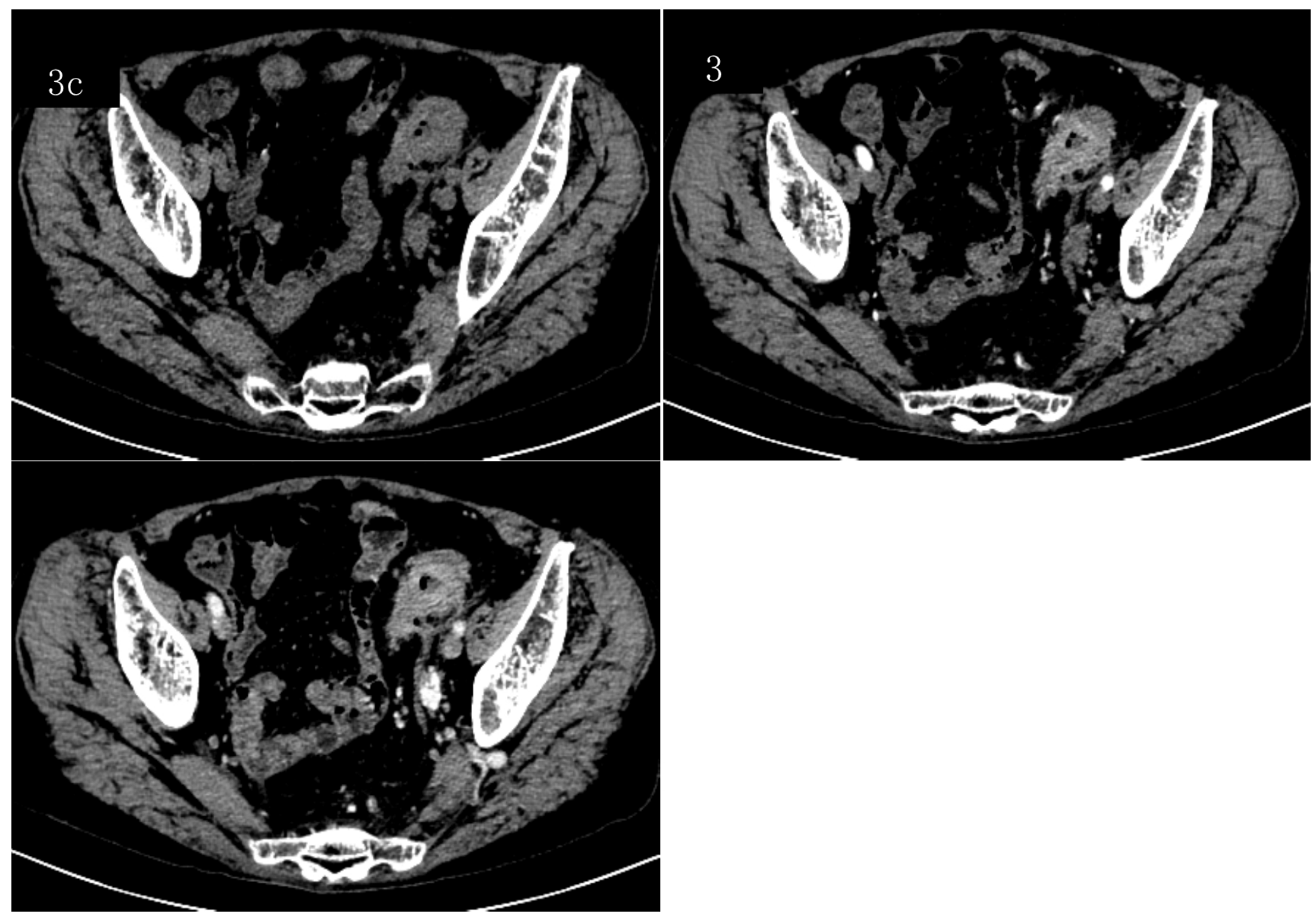

Figure 3

Abdomen and pelvic CT shows the thickened sigmoid wall with surrounding fatspace blurred. Mucosal involvement can be seen contributing to marked narrowing of the sigmoid colon. (a. non-contrast CT b. arterial phase of enhancement c. venous phase of enhancement ) 


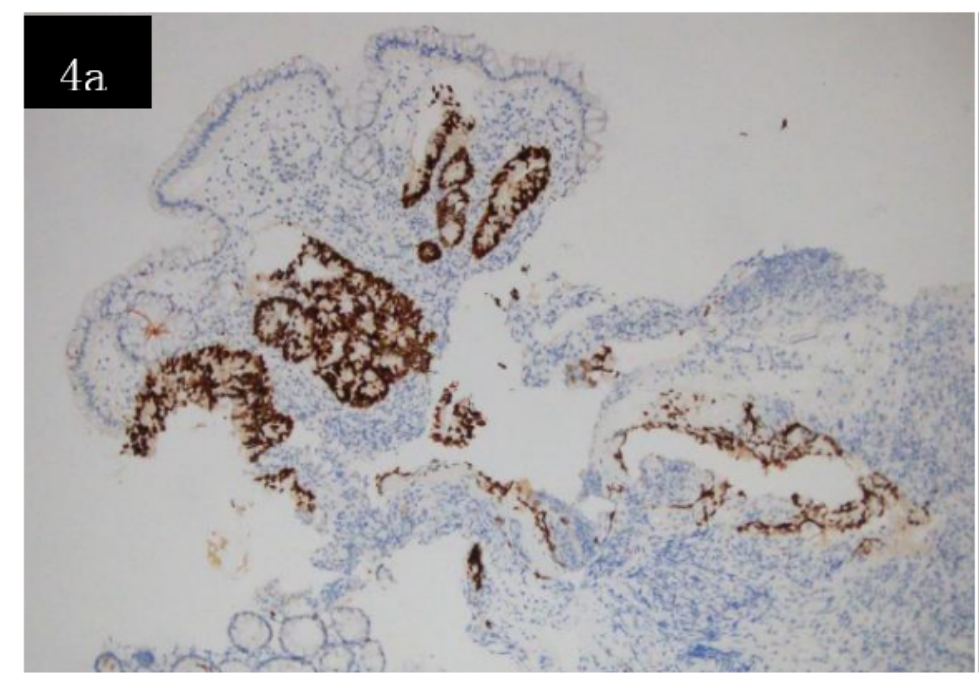

TTF-1

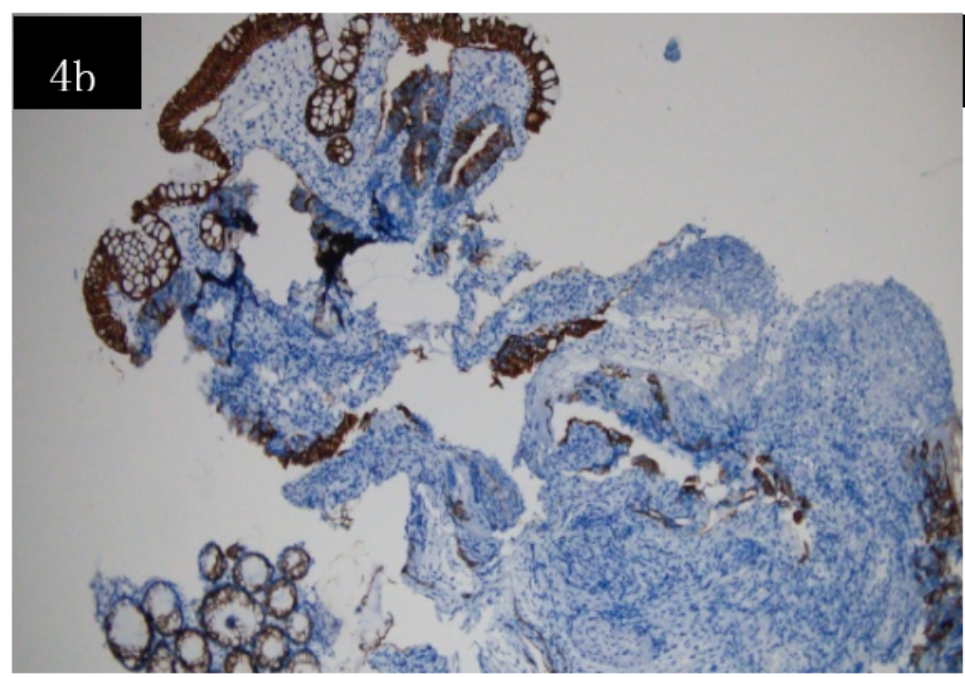

CK 20

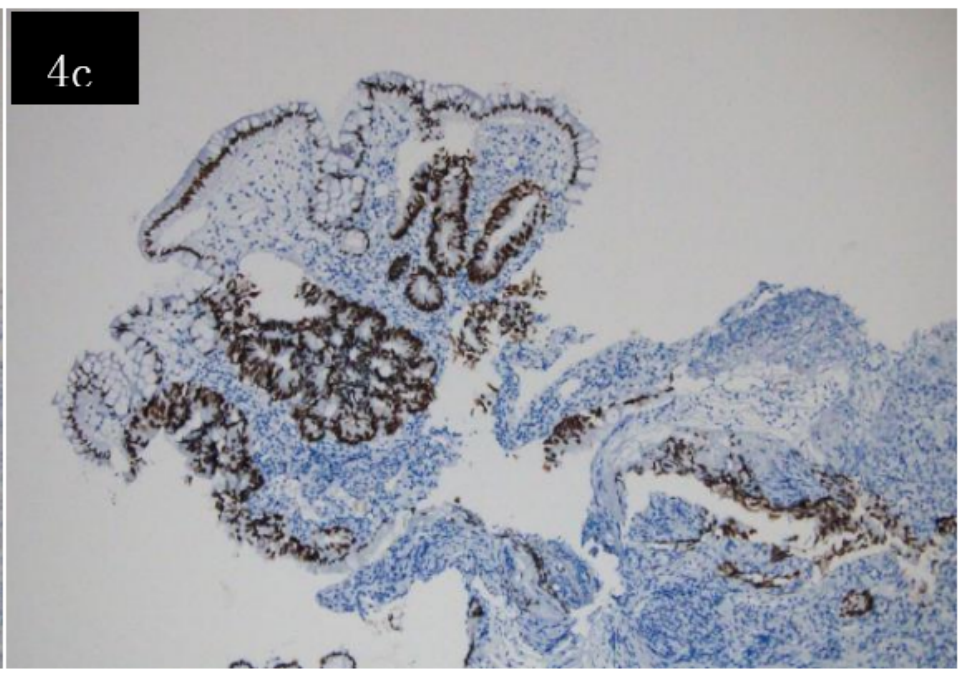

CDX2

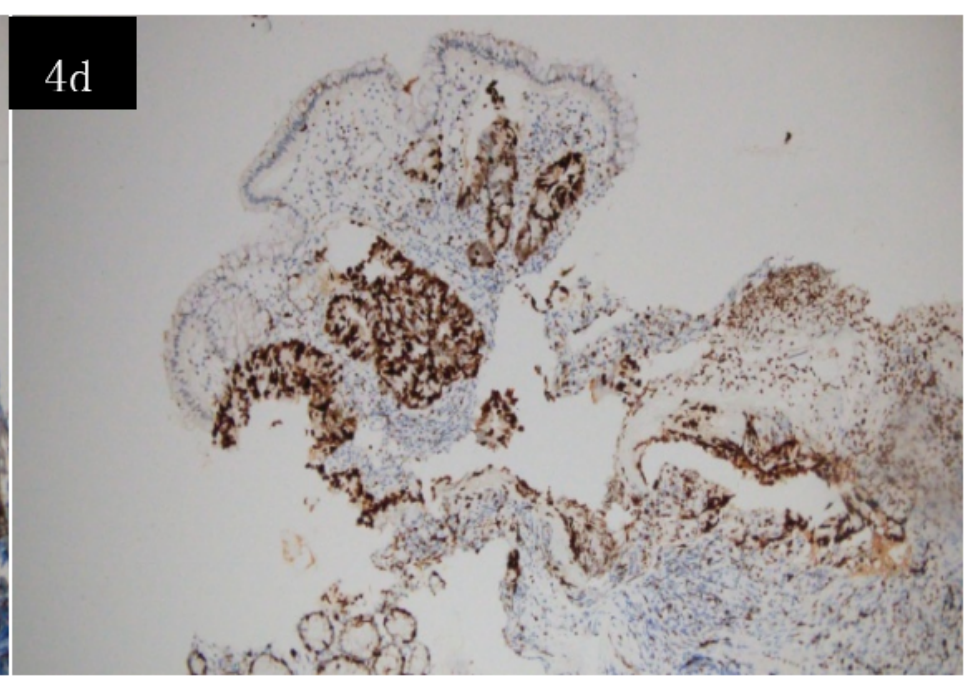

Ki67

\section{Figure 4}

The IHC of the colon. The carcinoma cells were positive for TTF-1, CK20 and CDX2, Ki-67(Li:80\%). 